\title{
Investigating the mediating role of organizational learning in the relationship between knowledge management aspects and organizational performance of sepah bank in Ardabil province
}

\author{
Daryoush Sahebnazar $^{1 *}$, Ebrahim Dadfar ${ }^{2}$ \\ ${ }^{1}$ Department of Management, Germi Branch, Islamic Azad University, Germi, Iran \\ ${ }^{2}$ Department of Management, Meshkin Branch, Islamic Azad University, Meshkin, Iran \\ *Corresponding author E-mail: dsahebnazar@gmail.com
}

\begin{abstract}
The organization's performance is considered as the qualitative and quantitative base of the development of any country. As long as the organizations do not conduct a survey to evaluate their knowledge assets, knowledge and organizational learning which are considered as the necessary parts of any organization, will not improve the performance and organizational development. Accordingly the aim of this study was to investigate the mediating role of organizational learning in the relationship between knowledge management aspects and organizational performance. The population of this study includes employees of Sepah Bank in Ardabil province branches, and sampling was conducted based on Morgan table which its number was equal to 169 and finally 164 questionnaires were analyzed. A questionnaire was used to collect the data and its reliability was investigated and has been approved using Cronbach's alpha coefficient. The collected data were studied using modeling techniques, structural equation, and bootstrapping. All of the stages were calculated using Stata and Lisrel software. The results showed that knowledge management aspects (knowledge creation, knowledge storage, knowledge sharing and application of knowledge) play a mediating role in the relationship between knowledge management and organizational performance.
\end{abstract}

Keywords: Knowledge Management; Organizational Learning; Organizational Performance; Sepah Bank.

\section{Introduction}

There is a growing conception in the field of trade with regard to the importance of knowledge as a critical resource for organizations. In the new economy, individuals and organizations have emphasized on maintaining and enhancing their knowledge capital for innovation and creativity. Although knowledge management is relatively an old concept, but approaching the mid-1980s and revealing the importance of knowledge and its impact on maintaining competitiveness in economic markets caused knowledge management to be an important issue. It was in 1980 decade that systems based on artificial intelligence and intelligent systems were used for knowledge management and concepts such as "knowledge acquisition," "knowledge engineering", "knowledgebased systems", and the like became vogue [1].

The good performance to gain insight and correct judgment about the efficiency and effectiveness of programs, processes, and their employees is one of the remarkable features of leading organizations, whether public or private. However, excellent organizations not only will not stay stopped in collecting and analyzing information on performance, but also using performance management, they will conduct the improvement and successfully convert and translate strategies into specific actions [2]. In addition, the field of competition compels organizations to face with the need to improve organizational performance and continuous improvement of organizational performance, creates great force of synergy for the organization. As a result, these forces can support the plan for growth and development opportunities for organizational excellence. In a simple phrase, organizational performance is the set of organizational mechanisms that have been introduced as a guiding light for all organizational and management activities and growth and sustainable development of organizations and national economic growth as one of its consequences depends on evaluation, measurement, analysis, comparing, and taking necessary measures in this regard [3]. As long as organizations are struggling to survive and feel the need for participation in national and international arena, have to preserve the principle of performance continuous improvement in their activities. This principle will not be met unless the context of achieving it is possible through improving performance management. This improvement can be met through getting necessary feedback from the inner and around environment, analyzing the organization's strengths and weaknesses and its opportunities and threats, being responsible and gaining organizational knowledge via creating and implementing performance measurement system with an appropriate model [6]. In the meantime, learning at the level of organization causes the minds of experts to remain as unknown black boxes and also limits the exchange between experts which has the most important role in increasing organizational knowledge. Learning must change into the knowledge of "exchanging the knowledge is power generator". The transition to this kind of knowledge in the organizations requires planned effort and proper management of learning at all the organizational levels. Organizational learning is directly related to an organization's competitive strength and in fact, the learning 
level of the organization can be compare with what is known as an organization's need to its strategic implementation and the need to improve organizational performance and the development of inclusive learning to achieve an acceptable level of learning process motivates [7]. Finally, it can be acknowledged that, through analyzing the knowledge and the importance of its features in the field of organizational performance, it is understandable that to have the knowledge and updated information for the survival of the organizations and improving their performance has become an undeniable necessity. Especially if the process of changing knowledge in the society be evaluated carefully. This result is also obtained that today's post-industrial society is an information society within which power increasing technologies gradually replaced by knowledge increasing technologies and it is essential for enterprises to continuously implement the new knowledge in the form of creation, validation, and application in their products and services in today's complex and dynamic environment [3]. According to the requirements which have been mentioned above, it can be argued that organizational knowledge and organizational learning and, more importantly, knowledge management are considered as the essential elements of any organization. Both issues are necessary and attractive but do the organization's efforts for knowledge management are always successful? What causes should de searches for in the case of knowledge management failure in the organization, and indeed what is be the main causes of knowledge management system failure in the organizations? Therefore, the major probable problems of Sepah Bank, retirements of the employees, and their transfer between different branches create a new challenge to retain knowledge and maintaining the organizational memory and consequently training the new employees. Over time, the bank's current employees will be retired in a few years. As a main problem this issue is facing many organizations including Sepah Bank. Meanwhile, through initiative, Sepah Bank requires to maintain the senior staffs' knowledge and provide other staffs with the context to transfer and learn their knowledge. Otherwise a vacuum of knowledge will occur in staff level and this will impose the training and development costs of human resources on the banks. Accordingly, the basic question of this study is to determine the mediating role of organizational learning in the relationship between knowledge management and organizational performance of Sepah Bank in Ardabil Province.

\section{Theoretical background and review of liter- ature}

For a long time, knowledge management and organizational learning in practice were considered as almost separate facts; however, they share some elements. Moreover, the evolution of both processes, posed important questions about whether organizations can survive rapid changes in the field of economy, society and the workplace. However, it is time to think and to have a closer look to knowledge management and organizational learning. Knowledge management is not merely an internal process, but an external process, and it's also not an event, but a key action and capability. It is better for knowledge management to be located in the center and be protected by fundamental elements, such as shareholders (e.g., unions and employees), customers, investors, leadership, and organization. Creation of ideas is not one of the greatest challenges organizations face, but their spread throughout the organization. When organizations gain access on the operating bases (information) and geographic boundaries, the share of ideas disappears. Moreover, the human tendency to store information is considered as a power tool which leads to weakening of the creation of knowledge. The structure of the knowledge and learning of many organizations is a turbulent structure, and in fact, each of them is inadequate and incapable while alone. For optimal learning and knowledge be distributed throughout the organization after its production, it is absolutely essential that people (for example, project teams and business associations) work together and be free in receiving and sending information. In fact, in order to support the production, distribution, and management of information and ultimately knowledge creation, structure has of necessity. Therefore, knowledge management such as organizational learning is a process. Combining these two with considering their history, strengths, and limitations is a challenge. The first step is to create a dialogue between the organization's authorities and stakeholders. Failing to bring these people to take a part in dialogue can lead to worries, fears, fantasies, and etc. Commitment to maintain databases is a way towards knowledge management and organizational learning. Establishing ongoing dialogue can lead to the creation of a common outlook and context for the organization. This will be realized through mutual respect and trust, taking the aforementioned steps, and accumulation of information. The focus should be on how to actively perform in order to achieve the culture of learning, so that knowledge management and organizational learning be investigated as two entangled process?

The management reveals leadership and commitment to learning and through designing appropriate behaviors and identifying those employees who freely share (participate) makes knowledge common. What people learn will not be stored but they will freely and without supervision shared this information. Trust is the basis of evident distribution of knowledge. Business associations and cross-functional networks virtually and personally support collaborative learning and knowledge creation. Creative problem solving, innovation, and questioning, are extremely valuable and are formalized. Thinking and research as the important elements in work processes in both the individual and team work levels are invaluable. Knowledge is created by people and technology as a means, not as a master, serves the organization. The creation of knowledge includes the spontaneity and the appearance of selforganized networks. Test (e.g., piloting) in the knowledge proficiency test, codifying and methods of transfer is of importance and includes both quantitative and qualitative measurement processes. Structure is an important part of the process, but in fact, our concern is to ensure that the spontaneity, creativity and innovation will not quenched [4].

On the other hand organizational learning is the origin of the need to evolve and getting better. It is obvious that with the evolution and development of mankind's knowledge, the need for change in the mechanisms of learning will be increased. In recent years, considerable attention has been devoted to e-Learning and it was of prosperity. Along with the spread and development of new technologies in the field of education, new styles in educational activities came into existence which today is called "blended learning". "Blended learning", as a new mechanism, has emphasized on using a wide variety of organizational learning methods which are considered necessary to improve organizational performance. Paying attention to the selection and use of the appropriate tools in order to raise the level of performance is one of the basic principles of organizational learning. Through using various methods and advanced technologies, organizational learning tries to improve the performance and organizational development in two horizontal or vertical dimensions [6]. Several studies have been conducted in relation to the subject that will be mentioned later.

In a study on "providing the critical success factors of knowledge management in order to increase creativity and organizational learning in the country's airports companies", through creating 14 minor and three main hypothesis, Hassan Beygi [5] concludes that there is a positive significant relationship between the independent variables (7 key factors in knowledge management success) and dependent variables (creativity and organizational learning) in the individual level and without interaction (based on regression analysis). But when interaction and relationship between knowledge management success key factors in combination with each other and the effect of independent variables on the dependent variables were established, only two factors of knowledge based strategies and human resources management lead to the increase of both organizational creativity and learning in the organization (according to the analysis of structural equation model). In the final model 
which has been presented by Hassan Beygi [5] interactions and contractions of each of research variables is shown clearly.

In a research on "investigating the effect of knowledge management on organizational learning and creativity from the perspective of executive directors of Ardabil province" using multiple regression and correlation analysis, Abdollahi [3] showed that knowledge management has a significant effect on organizational learning and organizational creativity. The research findings also clearly show that organizational learning is the connecting loop between knowledge management and organizational creativity and thereby provides promotion of creativity.

In a study titled "systemic approach to the effect of knowledge management, organizational learning and organizational creativity", Liao and $\mathrm{Wu}[8]$ concluded that knowledge management has a significant and positive impact (60.84) on organizational learning. In other words, knowledge management 60.84 establishes the organizational learning variance. In simple words, the knowledge management 60.84 improves organizational performance. On the other hand, according to the results of this study, knowledge management 6.76 establishes the variance of organizational creativity variable. In other words, knowledge management 6.76 has effect on organizational creativity.

In a study on "the effect of knowledge management and organizational learning on aspects of organizational performance", Hui et al [6] concluded that knowledge management and organizational learning has a positive significant effect on aspects of organizational performance (managers' performance, employees' performance, organizational processes' performance and customers' satisfaction). The findings also clearly showed that knowledge management variable and organizational learning has the greatest effect on employees' performance.

\section{Theoretical framework}

The variables under study in this research include knowledge management, organizational learning and organizational performance. The conceptual model of this research is listed below, which shows the relationship between variables. In this research, knowledge management variable, and its dimensions and indicators as the independent variable from the study of Liao and $\mathrm{Wu}$ [8] and Hui et al [6] and organizational performance variable as the dependent variable from the study of Hui et al [6] and organizational learning variable as the intermediary (mediator) variable from the study of Liao and $\mathrm{Wu}[8]$, Wera and Mary [9] and Hui et al [6] were derived and through studying these researches, the following model is formed in a combination.

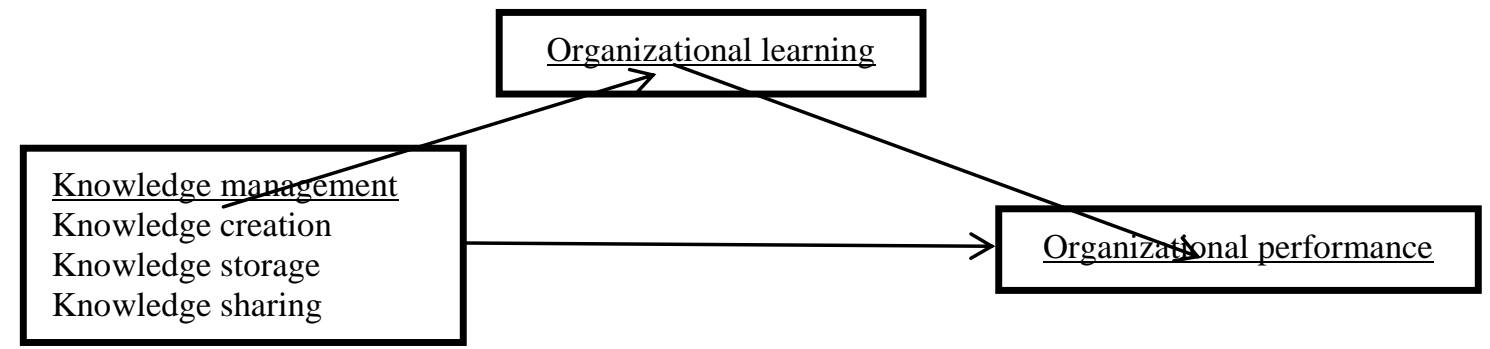

Fig. 1: The Conceptual Model of Research.

According to the described subject and conceptual model of research, regarding the investigation of the role of organizational learning as an intermediary (mediator) variable on the relationship between knowledge management dimensions and organizational performance the developed hypotheses of this study are as follows.

Hypothesis 1: Organizational Learning has a mediating role (mediator) in relation to the knowledge creation and organizational performance.

Hypothesis 2: Organizational Learning has a mediating role (mediator) in relation to the knowledge storing and organizational performance.

Hypothesis 3: Organizational Learning has a mediating role (mediator) in relation to the knowledge sharing and organizational performance.

Hypothesis 4: Organizational Learning has a mediating role (mediator) in relation to the application of knowledge and organizational performance.

\section{Research methodology}

The present study is practical with regard to its aim, because its findings can be used for the effectiveness knowledge sharing activities in the organization. From the perspective of how to collect the data, it considered as a descriptive survey, because it tries to gather information using the questionnaire from the sample. From the perspective of time is cross-sectional and from the perspective of the type of data is a quantitative research. The study population included all employees, deputies and heads of 30 branches of Sepah Bank in Ardabil province are. The sample group consisted of 169 people, was selected and studied according to Morgan table through relatively simple random. A questionnaire was used to collect the data. Research questionnaires intended to collect the data consists of 56 questions. 21 questions related to organization- al learning by Nife et al. (1990), 15 questions related to organizational performance by Stevenson (1998) and 20 questions related to the knowledge management by Spreitzer (1997) (includes measurement of indicators such as knowledge creation, knowledge storage , knowledge sharing and knowledge application). The questionnaire which was used in this study is standard that due to being standard its validity is confirmed. Cronbach's alpha was used in order to determine the reliability of measurement instruments. Cronbach's alpha coefficient for the questionnaires is shown in Table 1. It can be said that the questionnaire had acceptable reliability.

Table 1: Reliability Coefficients of the Questionnaire

\begin{tabular}{ll}
\hline Questionnaire & The value of Cronbach's alpha coefficient \\
\hline Knowledge management & 0.805 \\
Knowledge creation & 0.804 \\
Knowledge storage & 0.789 \\
Knowledge sharing & 0.811 \\
Knowledge application & 0.789 \\
Organizational learning & 0.861 \\
Organizational performance & 0.882 \\
\hline
\end{tabular}

\section{The research findings and testing the hy- potheses}

In this section we examine the research hypotheses. The results of Lisrel software output to estimate the conceptual model of research (standardized coefficients) in figure 2 and the significance of these coefficients in figure 3 have been shown. Based on the output of Lisrel software (table 2) RMSEA index is equal to 0.078. It can be said that the model is of excellent fitness. According to MySQL Pro chi normal index of 3.79 is achieved, which is also a suitable amount. Model parameters are shown in table 2 . The value of these indices is appropriate in the present study. So, the model is acceptable in this sense as well. Given that the fitness 
indices of the model reflect the appropriate fitness of the model, it can be concluded that the model of can structural equation is estimated appropriately. According to figure 2, it can be said that the dimensions of knowledge management directly and indirectly (through organizational learning) also have a positive impact on organizational performance. All coefficients are significant at the 0.05 level. Bootstrap and Preacher and Hayes [10] test methods with the Sata software is used to test research hypothesis and investigate the mediating role of organizational learning and knowledge management aspects of the relationship between organizational performance and indirect coefficients significant. The results of Bootstrap procedure for the intermediate routes are shown in table 3 .

To examine this hypothesis in table 3 if the lower and upper bounds for the desired route do not contain zero, indirect relationship (the mediating role of the variable) will be meaningful [10].
According to table 3, the lower limit and upper limit of the confidence interval for organizational learning as a mediating variable in the relationship between dimensions of knowledge management and organizational performance does not include zero. Confidence level for this interval is 95 percent and the number of Bootstrap sampling is 5000. Since zero is placed outside this confidence interval, the indirect relationship between the dimensions of knowledge management and organizational performance through organizational learning is meaningful. Therefore, due to the significant relationship between dimensions of knowledge management and organizational performance through organizational learning, it follows that organizational learning in the relationship between knowledge management and organizational performance plays a mediating role. So it follows that the research hypothesis is confirmed with 95 percent of confidence.

Table 2: The Goodness of Fit Statistics

\begin{tabular}{ll}
\hline Statistics & Value \\
\hline CFI & 0.91 \\
GFI & 0.92 \\
AGFI & 0.90 \\
NFI & 0.90 \\
IFI & 0.91 \\
RMSEA & 0.079 \\
Chi-square/df & 3.79 \\
CFI & 0.91 \\
GFI & 0.92 \\
\hline
\end{tabular}



Fig. 2: Standardized Coefficients. 


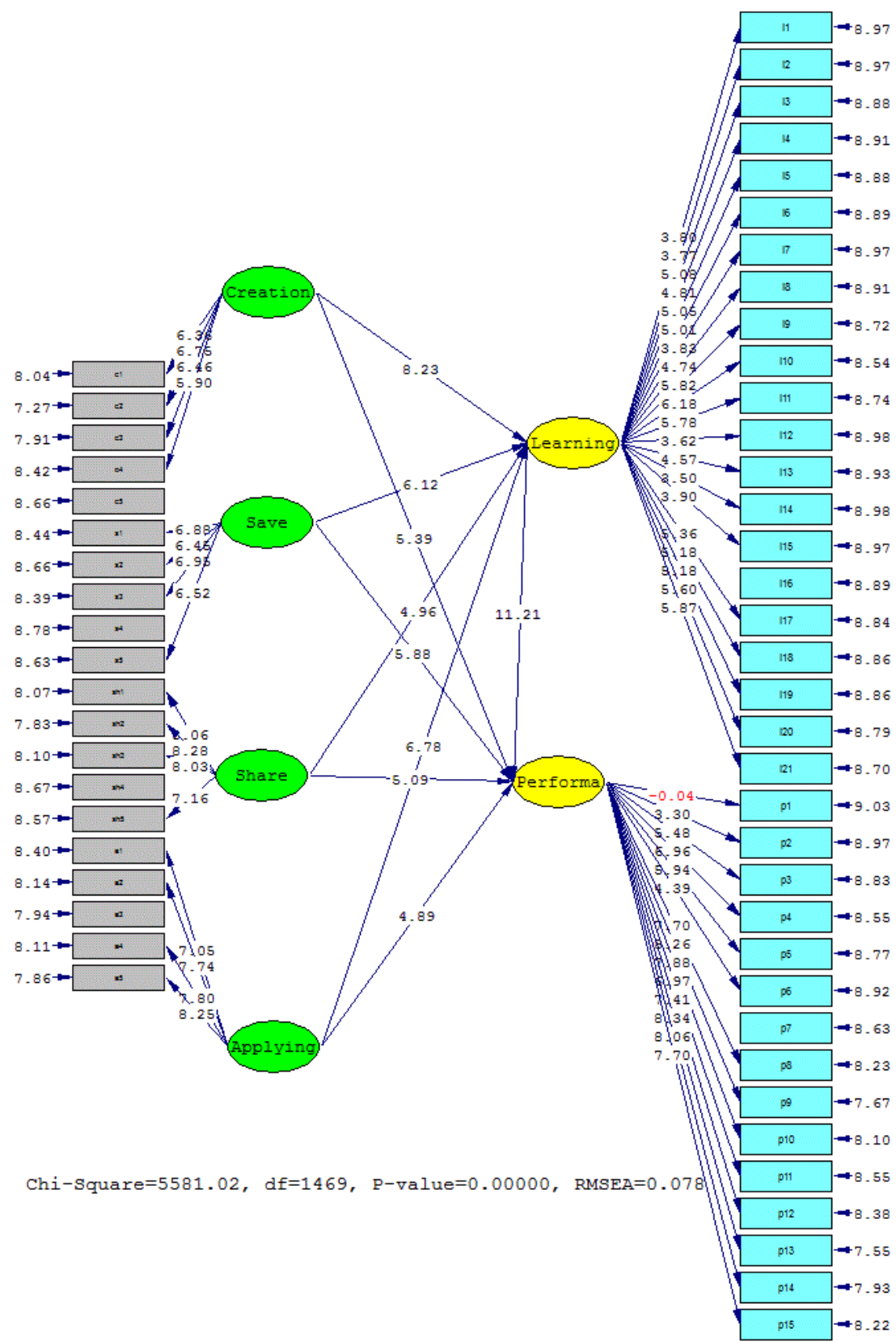

Fig. 3: Significant of Coefficients (T-Value).

Table 3: Bootstrap Test

\begin{tabular}{|c|c|c|c|c|}
\hline & coefficient & sig & lower limit & Upper limit \\
\hline Knowledge creation $\rightarrow$ Organizational learning $\rightarrow$ Organizational performance & 2.26 & 0.000 & 1.87 & 2.69 \\
\hline Knowledge storage $\rightarrow$ Organizational learning $\rightarrow$ Organizational performance & 1.84 & 0.000 & 1.38 & 2.39 \\
\hline Knowledge sharing $\rightarrow$ Organizational learning $\rightarrow$ Organizational performance & 1.49 & 0.000 & 1.12 & 1.91 \\
\hline Knowledge application $\rightarrow$ Organizational learning $\rightarrow$ Organizational performance & 1.88 & 0.000 & 1.42 & 2.42 \\
\hline
\end{tabular}

\section{Conclusion}

Organizational knowledge and organizational performance are two central members that is necessary for them to adapt themselves with scientific and technological changes and developments in the society. Today, one of the criteria for evaluating successful managers can be identify through growth, ingenuity, and innovation and organizational knowledge management and learning of its staffs and how much managers have tried to improve the level of knowledge of subordinates and their organizations to enhance the performance of their organization. The feeling of fatigue could be due to compulsory. The highest level of learning will be occurred when the person's explicit knowledge management is considered. More the people be aware of the results of their work on the collective learning, they will be more responsible towards improving the outcomes of the activities and thus will lead to increased organizational performance. Therefore, people can be empowered with knowledge management and learning and, ultimately, increased organizational performance. The head of an organization have to value its employees based on the knowledge features and efforts to learn and transfer the knowledge. Since remaining competitive is a continuous struggle for all of the organizations in the twenty-first century business environment, the learning organizations encourage their employees to improve their personal and team skills and the quality of their work. They make use of their own experience and others that may be useful or negative. People are admired with their skills and values and all opinions and suggestions are respectful. Through reviewing the literature on three variables of knowledge management, organizational learning and organizational performance it is revealed that the finding of this study is similar to the results of Liao and $\mathrm{Wu}[8]$ which confirmed 
the existence of a significant relationship between the three variables of knowledge management, organizational learning and organizational performance. The results also showed that organizational learning is an interface loop between knowledge transfer and organizational performance. Given that organizational learning is an interface loop between knowledge management dimensions and organizational performance, due to the vital role of knowledge and organizational performance it is suggested to the managers of Sepah Bank branches in Ardebil province to put more effort to improve and enhance their knowledge and organizational performance in Sepah Bank branches in Ardebil province through organizational learning. In this regard, it appears that people's trust, as a working and occupational strategy, should perform simultaneously on multiple borders and is considered as a means for the overall progress of a bank's program and provides power to meet external challenges within the organization and this will be carried out through utilization of knowledge resources in personnel, information resources, information technology and its applications, as well as through relationships with customers and other stakeholders will be. Management of people's trust is somehow a strategic management and their presupposes are that directors and managers of Sepah Bank branches in Ardebil province specifically make use of full exploitation of opportunities for working purposes. Also believe that all of the competitors are leading in this respect.

\section{References}

[1] Latifian A, Amiri Q, Knowledge management in non-formal education system in universities based on the theory of Nonaka and Takeuchi. Information Quarterly, 2012, 9: 114-126.

[2] Hekmat M, The effects of knowledge management on performance. Master's thesis, Faculty of management, Islamic Azad University Boroujerd branch, 2013

[3] Abdollahi M. investigating the effect of knowledge management on organizational learning and creativity from the perspective of executive directors of Ardabil province. First National Conference on Economy and management on a national approach, Babolsar, Mazandaran University,2014, 11-12 Mehr, p 210-218.

[4] Babaei A, Integration of knowledge management and organizational learning. Monthly educational-science journal of Tadbir, 2010, 196: 10-33.

[5] Hasan Beygi M, Providing the critical success factors of knowledge management in order to increase creativity and organizational learning in the country's airports companies. Master's thesis, Faculty of Engineering Payamenoor University of Tehran, 2010.

[6] Hui H, CheWan J, HashemSalarzadeh J, Kheirollahpour M, Son R, Impact of knowledge management and organizational learning on different dimensions of organizational performance: a case study of Asian food industry. Interdisciplinary Journal of Contemporary Research in Business, 2013, 3: 148-155.

[7] Noe R, Wang S., Knowledge sharing: A review and directions for future research, Human Resource Management Review, 2010, 1: $113-135$

[8] Liao S, Wu, C, System perspective of knowledge management, organizational learning and organizational innovation. Expert Systems with Applications, 2010, 2: 1096-1103. http://dx.doi.org/10.1016/j.eswa.2009.06.109.

[9] Vera D, Mary C., Organizational learning, knowledge management, and intellectual capital: an integrative conceptual model. International Journal of Business and Management, 2012, 4: 100-110.

[10] Preacher, K. J., \& Hayes, A. F., Asymptotic and resampling strategies for assessing and comparing indirect effects in multiple mediator models. Behavior Research Methods, 2008, 40, 879-891. http://dx.doi.org/10.3758/BRM.40.3.879. 